
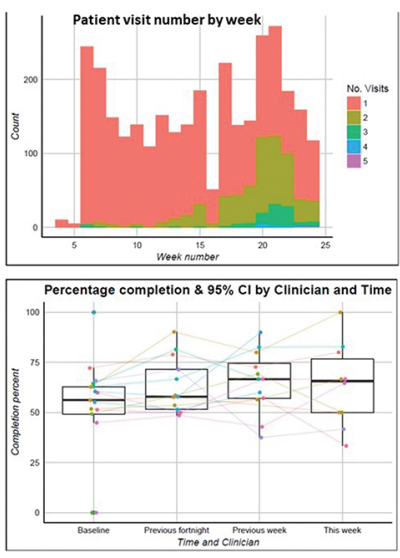

Figure 2. Predictors of Survey Response
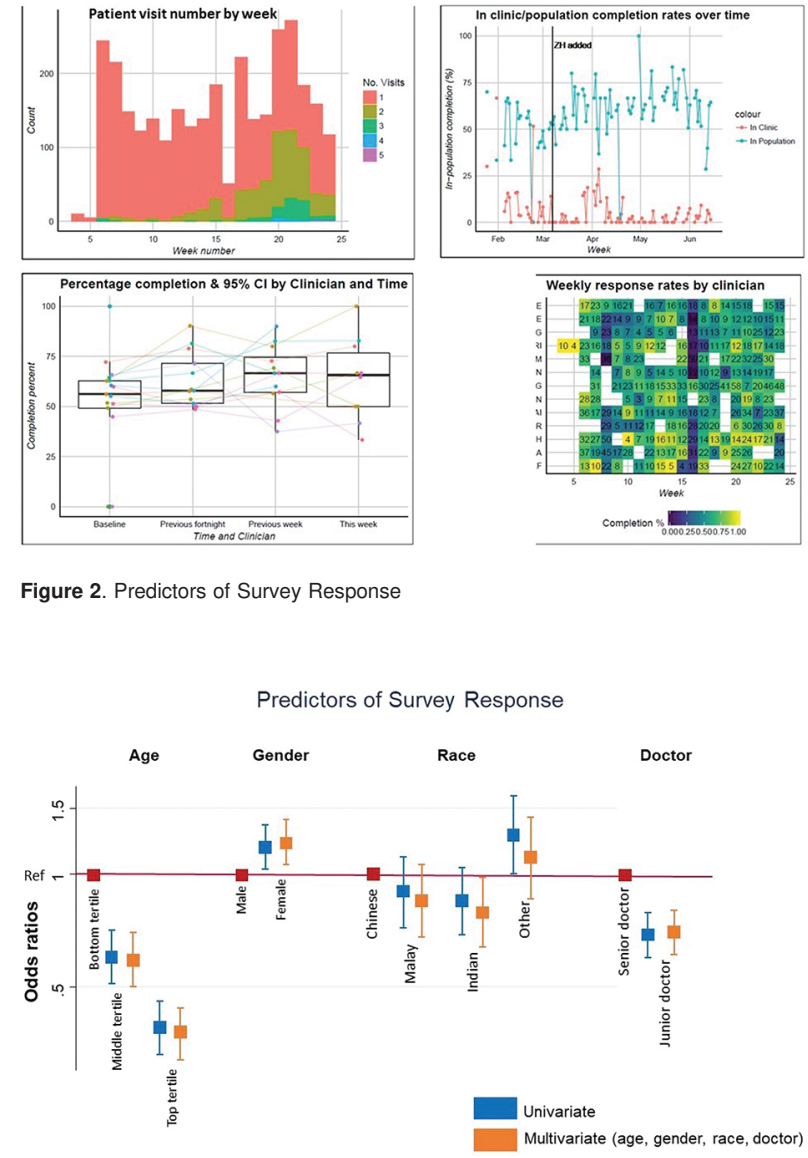

Acknowledgement: Ramasamy Thirumugam from the Academic Informatics Office, National University Hospital, for setting up the system

Disclosure of Interests: Manjari Lahiri Grant/research support from: Grant support from Pfizer. I am the site PI for the Singapore National Biologics Register which is funded by multiple pharmaceutical companies; however I do not directly receive any funds for this., Consultant for: Advisory board for Elli Lilly, James Yip: None declared

DOI: 10.1136/annrheumdis-2019-eular.3872

\section{THU0640 EARLY RETIREMENT ATTRIBUTED TO RHEUMATOID ARTHRITIS AND ITS PREDICTORS IN PORTUGAL}

Mariana Luis ${ }^{1}$, Ana Rita Cunha ${ }^{2}$, Helena Assunção ${ }^{1}$, Ana Rita Prata ${ }^{1}$ Luisa Brites ${ }^{1}$, Flavio Costa ${ }^{1}$, João Dinis de Freitas ${ }^{1}$, Stephanie Silva', Anabela Barcelos ${ }^{2}$, Catia Duarte ${ }^{1}$, José Antonio P. Da Silva ${ }^{1} .{ }^{1}$ Centro Hospitalar e Universitário de Coimbra, Coimbra, Portugal; ${ }^{2}$ Centro Hospitalar do Baixo Vouga, Aveiro, Portugal

Background: Work disability is a common consequence of Rheumatoid Arthritis (RA) with economic implications for both the patient and society. Scarce information is available on work and disease-related factors associated with early retirement in Portugal.

Objectives: To evaluate the rate of early retirement due to RA. Secondary aim consists in the identification of its main predictors, both work and disease-related.

Methods: Retrospective cohort study involving two national rheumatology centers, including patients with RA according the ACR/EULAR 2010 or the 1987 ACR Classification Criteria for RA. Patients retired prior to RA diagnosis, never-employed or with missing information on current work status were excluded. Type of work was independently classified as non-manual/ manual/heavy manual by two authors based on patient's occupation with excellent inter-agreement (Cohen's kappa coefficient 0.91). Retirement due to RA versus retirement for other reasons were compared using T-test and Chi-2 test as adequate. Variables with $p<0.05$ in univariate analysis and other potential predictors selected on clinical and epidemiological grounds were included in multivariable binary logistic regresssion.

Results: 492 patients were included $(80.3 \%$ female, aged $60.9 \pm 13.1$ years-old, mean disease duration $15.9 \pm 10.5$ years). Until the present time, $45.1 \%(n=222)$ of the patients retired, this being due to RA in
$59.5 \%$ of the cases. Early retirement due to RA translated into 6.5 years of active work lost, compared to retirement due to other causes. Patients who retired due to RA are more likely to be younger at diagnosis $(49.6$ \pm 9.0 vs. $56.1 \pm 8.6$ years-old; $p<0.01)$, female $(82.6 \%$ vs. $68.9 \%$, $\mathrm{p}<0.01)$, have longer disease duration $(23.2 \pm 10.7$ vs. $18.3 \pm 9.9$ years, $p<0.01)$ and lower educational level $(4.5 \pm 2.3$ vs. $6.0 \pm 4.1$ school years, $p<0.01)$. In the multivariate analysis, disease-related predictors for early retirement were: disease duration (OR: 1.11; $95 \%$ Cl 1.08-1.13/ year), erosive disease (OR: $4.4595 \% \mathrm{Cl} 2.37-8.35$ ) and the need for biologic therapy switching (OR:1.37; $95 \% \mathrm{Cl} 1.02-1.83$ ). Work-related predictors were: educational level (OR: $0.75 ; 95 \% \mathrm{Cl} 0.68-0.81 /$ year) and heavy manual type of work (OR: $1.62 ; 95 \% \mathrm{Cl} 1.16-2.26$ ).

Conclusion: Early retirement is still common among patients with RA: $60 \%$ in this cohort. The main reasons for early retirement are associated with the disease itself, but work-related factors also play a relevant role.

\section{REFERENCES:}

[1] P. A. Laires, M. Gouveia. Association of rheumatic diseases with early exit from paid employment in Portugal. Rheumatol Int (2014) 34:491-502.

[2] K. Puolakka, H. Kautiainen, T. Mottonen, P. Hannonen, et al. Predictors of productivity loss in early rheumatoid arthritis: a 5 year follow up study. Ann Rheum Dis 2005;64:130-133.

[3] D. Lacaille, S. Sheps, J. J. Spinelli, A. Chalmers, J. M. Escaile. Identification of modifiable work-related factors that influence the risk of work disability in rheumatoid arthritis. Arthritis Rheum. 2004 Oct 15;51(5):843-52.

Disclosure of Interests: None declared

DOI: 10.1136/annrheumdis-2019-eular.1635

\section{THU0641 USE OF A WEB-BASED RHEUMATOLOGY PATIENT MANAGEMENT PORTAL}

Tin Aung ${ }^{1}$, Robert Sharpe ${ }^{2}$, Roope Manhas ${ }^{1}$, Stuart Kyle ${ }^{1} .{ }^{1}$ Northern Devon Healthcare NHS trust, Rheumatology, Barnstaple, United Kingdom; ${ }^{2}$ Medimetric, Barnstaple, United Kingdom

Background: The benefit of incorporating tele-rheumatology into standard care is increasingly recognised. In January 2017, we introduced a webbased Rheumatology Patient Management Portal (RPMP), developed by MedMet, to our rheumatology patients at the North Devon District Hospital. In 2018 the portal service was fully operational. Suitable patients included undifferentiated inflammatory arthritis, rheumatoid arthritis, psoriatic arthritis and spondyloarthritides. Patients were consented to collected data such as diagnosis, treatment and disease activity onto the RPMP. For a selected group of patients who agreed to their email use, we set up schedules in the form of email reminders for them to complete PROMs (patient reported outcome measures) such as Health Assessment Questionnaire, Spinal Pain, Bath Ankylosing Spondylitis Disease Activity Index and Work Productivity and Activity Impairment. Patients can also report disease flares electronically, which is acknowledged by a health care professional who will contact them with advice as necessary.

Objectives: To understand patient participation in the use of the RPMP, between 01.01 .18 and 31.12.18.

To develop a cohort of clinically stable patients who can self-manage via RPMP use and scheduled PROMs. The potential to remotely manage these patients has the advantage of reducing the number of face-to-face clinic appointments and eventually will lead to setting up a virtual clinic. To examine patient perception on the RPMP use.

To examine whether tele-rheumatology is a useful adjunct to standard care. Methods: The data was collected from interrogating the web-based RPMP database. Specific data was reviewed including; total number of patients on the portal, number of patients consenting to use their email, number of PROMs completed on the RPMP, number of flares reported and time to acknowledgment. In order to gain further understanding of user experience, a survey questionnaire (figure 1) was sent on 14.01.19.

Results: In total we have 883 patients recruited to the RPMP.

During the study period of one year, 289 patients have consented to share their emails and set up schedules. Therefore $33 \%$ of patients on the RPMP are using their emails through 2018. 310 patients responded to their portal request to complete a schedule. 758 PROMs were completed as part of the schedule response. 1744 PROMs were completed face to face whilst in standard clinic review. Therefore, 30\% of PROMs were completed through a scheduled response. 55 patients contacted us through the RPMP to report a flare. The average time to acknowledging a flare is 37 hours. $78 \%$ of flare reports were acknowledged within 3 days. Results from the survey of patient experience as follow: number of patients responded to the survey was 99 and respond rate was $34 \%$. 
Among them, 94\% reported the RPMP as easy to use, 54\% found that RPMP helped them in understanding their rheumatology condition and $25 \%$ reported a flare through the RPMP.

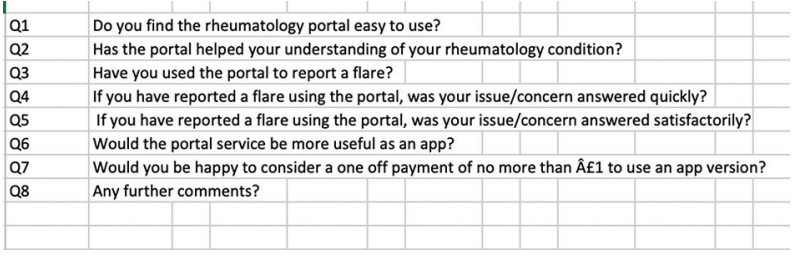

Conclusion: A large number of our rheumatology patients have consented to use the RPMP and their email. Uptake of the RPMP use is increasing (figure 2).

We have identified a significant proportion of 289 patients using the portal and email that could be targeted for virtual clinic use. Our data showed that use of tele-rheumatology in conjunction with standard care has potential to reduce number of standard clinic appointments however further work is required to investigate this.

Feedback from clinical staff is that having PROMs completed prior to consultation gives more time to discuss key issues whilst facilitating appropriate monitoring. The survey showed that majority of patients found the RPMP easy to use and helpful in understanding their rheumatology condition. The RPMP is an effective monitoring system for selected patients and has improved patient understanding in monitoring their disease activity.

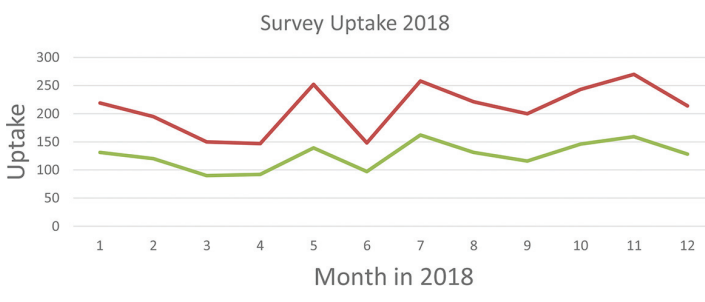

Disclosure of Interests: Tin Aung: None declared, Robert Sharpe: None declared, Roope Manhas: None declared, stuart kyle Consultant for: but no conflict of interest.

DOI: 10.1136/annrheumdis-2019-eular.3311

\section{THU0642 EULAR POINTS TO CONSIDER FOR THE DEVELOPMENT, EVALUATION AND IMPLEMENTATION OF MOBILE HEALTH APPLICATIONS FOR SELF- MANAGEMENT IN PATIENTS WITH RHEUMATIC AND MUSCULOSKELETAL DISEASES}

Aurelie Najm $^{1,2}$, Elena Nikiphorou ${ }^{3}$, Marie Kostine ${ }^{4}$, Christophe Richez ${ }^{4}$, John Pauling ${ }^{5}$, Axel Finckh ${ }^{6}$, Valentin Ritschl ${ }^{7}$, Yeliz Prior ${ }^{8}$, Petra Balazova ${ }^{9}$ Simon Stones ${ }^{10}$, Zoltán Szekanecz ${ }^{11}$, Annamaria lagnocco ${ }^{12}$, Sofia Ramiro ${ }^{13}$, Francisca Sivera ${ }^{14}$, Maxime Dougados ${ }^{15}$, Loreto Carmona ${ }^{16}$, Gerd Rüdiger Burmester ${ }^{17}$, Laure Gossec ${ }^{18}$, Francis Berenbaum ${ }^{19}$. $^{1}$ Nantes University Hospital, Rheumatology, Nantes, France; ${ }^{2}$ INSERM UMR 1238 University of Medicine Nantes, Nantes, France; ${ }^{3}$ King's College London, Rheumatology, London, United Kingdom; ${ }^{4}$ Bordeaux University Hospital, Rheumatology, Bordeaux, France, ${ }^{5}$ Royal National Hospital for Rheumatic Diseases, Bath; and Department of Pharmacy and Pharmacology, University of Bath, United Kingdom, Bath, United Kingdom; ${ }^{6}$ Service de Rhumatologie Hôpital Beau-Séjour, Hôpitaux Universitaires de Genève, Geneve, Switzerland; ${ }^{7}$ Medical University of Vienna, Section for Outcomes Research, Vienna, Austria; ${ }^{8}$ Centre for Health Sciences Research, University of Salford, Salford and Mid Cheshire NHS Foundation Trust Hospitals, Crewe, United Kingdom; ${ }^{9}$ EULAR Young PARE, Zurich, Switzerland; ${ }^{10}$ University of Leeds, Leeds, United Kingdom; ${ }^{11}$ University of Debrecen, Debrecen, Hungary, ${ }^{12}$ Academic Rheumatology Centre, Università degli Studi di Torino, Italy, Torino, Italy; ${ }^{13}$ Leiden University Medical Centre, Leiden, Netherlands; ${ }^{14}$ Hospital General Universitario de Elda, Elda, Spain; ${ }^{15}$ Hopital Cochin, Paris, France; ${ }^{16}$ Instituto de Salud Musculoesquelética, Madrid, Spain; ${ }^{17}$ Charité University Clinic, Berlin, Germany; ${ }^{18}$ Sorbonne Université, Pitié Salpétriere Hospital, Paris, France, ${ }^{19}$ Sorbonne Université, Saint Antoine Hospital, Paris, France

Background: In the expanding era of e-health, a wide range of mobile health applications (apps) have become available to enable people with rheumatic and musculoskeletal diseases (RMDs) to better self-manage their health. However, guidance on the development and evaluation of such apps is lacking.

Objectives: The objective of this EULAR task force was to establish points to consider (PtC) for the development, evaluation and implementation of apps for self-management of RMDs.

Methods: A systematic literature review of app content and development strategies was conducted, followed by a qualitative study with six patients and an online survey of people living with RMDs $(n=394)$. Based on these data and expert opinion, the PtC were formulated in a face-to-face meeting in November 2018 by a multidisciplinary TF panel of experts, including patients, from 10 countries. The level of agreement among the panel in regard to each $\mathrm{PtC}$ was established by anonymous online voting.

Results: Three overarching principles and 10 PtC were formulated (Table). Out of the $10 \mathrm{PtC}$, three were related to patient safety $(1,5,6)$, considered as a critical issue by the panel, along with accuracy of information provided by apps. Three were related to relevance of the content and functionalities $(2,7,9)$ and the importance of apps being tailored to the individual needs of people with RMDs. The requirement for transparency around app developers and funding sources $(3,4)$, along with involvement of relevant health professionals were also raised. Ease of app access across ages and abilities was highlighted (8), in addition to considering the cost-benefit of apps from the outset (10). The level of agreement was high (Table).

Conclusion: These PtC provide guidance on important aspects that should be considered for the development of new apps, the quality assessment of existing apps, as well as for further development of existing apps. As part of the dissemination phase, these PtC will be shared with a larger group of health professionals, patients and app developers and for wider consensus.

\begin{tabular}{|ll|c|}
\hline \multicolumn{1}{|c|}{ Points to consider } & $\begin{array}{c}\text { Level of agreement } \\
\text { mean (SD) }\end{array}$ \\
\hline 1. & $\begin{array}{l}\text { The information content in self-management Apps should be up to date, } \\
\text { scientifically justifiable, user-acceptable and evidence-based where } \\
\text { applicable. }\end{array}$ & $9.8(0.4)$ \\
\hline 2. & $\begin{array}{l}\text { Apps should be relevant and tailored to the individual needs of people with } \\
\text { RMDs. }\end{array}$ & $9.7(0.5)$ \\
\hline 3. & $\begin{array}{l}\text { The design, development and validation of a self-management App should } \\
\text { involve people with RMDs and relevant health care providers. }\end{array}$ & $9.8(0.6)$ \\
\hline $4 . \quad \begin{array}{l}\text { There should be transparency on an Apps' developer, funding source, content } \\
\text { validation process, version updates and data ownership. }\end{array}$ & $9.9(0.3)$ \\
\hline 5. & $\begin{array}{l}\text { Data collection as part of an App must adhere to all applicable regulatory } \\
\text { frameworks, particularly data protection. }\end{array}$ & $9.9(0.3)$ \\
\hline 6. & Apps must not result in physical or emotional harm to people with RMDs. \\
\hline 7. & $\begin{array}{l}\text { Apps could facilitate patient-health care provider communication and } \\
\text { contribute to electronic health records or research. }\end{array}$ & $9.3(1)$ \\
\hline 8. & $\begin{array}{l}\text { App design should consider accessibility of people with RMDs across ages } \\
\text { and abilities. }\end{array}$ & $9.4(0.9)$ \\
\hline 9. & $\begin{array}{l}\text { If a social network is an important component of an App, structures should } \\
\text { be in place to ensure appropriate content moderation. }\end{array}$ & $9.4(0.9)$ \\
\hline 10. & $\begin{array}{l}\text { The rheumatology community should consider the cost-benefit balance of } \\
\text { Apps before its endorsement and/or its promotion. }\end{array}$ & $9.5(0.6)$ \\
\hline
\end{tabular}

Table 1. The 10 Points to Consider.

Acknowledgement: EULAR for funding this project

Disclosure of Interests: Aurelie Najm: None declared, Elena Nikiphorou: None declared, Marie Kostine: None declared, Christophe Richez: None declared, John Pauling: None declared, Axel Finckh Grant/research support from: Bristol-Myers Squibb, Pfizer Inc, Consultant for: AbbVie, A2Bio Bristol-Myers Squibb, MSD, Roche, Pfizer Inc, and UCB, Valentin Ritschl: None declared, Yeliz Prior: None declared, Petra Balazova: None declared, Simon Stones Consultant for: SS has provided consultancy services to Envision Pharma Group, though this is not related to the contents of this abstract., Speakers bureau: SS has undertaken speaking engagements for Actelion, eyeforpharma, Four Health, Janssen and Roche, though these are not related to the contents of this abstract., Zoltán Szekanecz Grant/research support from: Pfizer, UCB, Consultant for: Pfizer, Abbvie, Roche, Sanofi, Lilly, Novartis, Speakers bureau: Pfizer Abbvie, Roche, Sanofi, Lilly, Novartis, Annamaria lagnocco: None declared, Sofia Ramiro Grant/research support from: MSD, Consultant for: AbbVie, Lilly, MSD, Novartis, Pfizer, Sanofi, Speakers bureau: AbbVie, Lilly, MSD, Novartis, Pfizer, Sanofi, Francisca Sivera: None declared maxime dougados Grant/research support from: Eli Lilly and Company, Pfizer, AbbVie, and UCB Pharma, Consultant for: Eli Lilly and Company, Pfizer, AbbVie, and UCB Pharma, Loreto Carmona Grant/research support from: Abbvie, Actelion, Astellas, BMS, Eisay, Gebro Pharma, Grünenthal, Leo Pharma, Lilly, MSD, Novartis, Pfizer, Roche, Sanofi-Aventis and UCB Pharma, Paid instructor for: Novartis, Gerd Rüdiger Burmester Consultant for: Roche, Sanofi-Genzyme, Speakers bureau: Roche, Sanofi-Genzyme, 